\title{
A ASCENSÃO DO TEMA DOS Direitos Humanos No Pós- GUERRA FRIA: A CONFERÊNCIA DE VIENA (1993)
}

\section{Matheus de Carvalho Hernandez ${ }^{1}$}

\begin{abstract}
RESUMO
Este artigo tem como objetivo analisar a Conferência Mundial para os Direitos Humanos de Viena (1993) como um marco em matéria de direitos humanos. A idéia central é demonstrar dois movimentos. Primeiro que a Conferência teve papel importante na universalização dos direitos humanos como ponto central na agenda dos Estados e como issue-area nas relações internacionais. 0 segundo refere-se à Conferência como contribuição para o processo de "flexibilização da soberania". 0 artigo está dividido em três eixos: na primeira se discutem os antecedentes que envolveram a Conferência de Viena nos anos 1990; depois se discute a relação entre direitos humanos e soberania estatal no sistema internacional; e, por fim, uma terceira seção que visa relacionar os dois movimentos a partir dos debates da Conferência.
\end{abstract}

Palavras-chave: Direitos Humanos. Relações Internacionais. Conferência de Viena. Soberania.

\footnotetext{
${ }^{1}$ Mestrando em Relações Internacionais \& Desenvolvimento pelo Programa de Pós-graduação em Ciências Sociais da UNESP-Marília. Bolsista FAPESP. End. eletrônico: matheush@marilia.unesp.br
} 


\section{THe RISE OF THE THEME OF Human Rights IN POST-COLD WAR: THE CONFERENCE OF VienNa (1993)}

\section{Abstract}

This article aims to analyze the World Conference on Human Rights in Vienna (1993) as a milestone in human rights. The central idea is to show two movements. First, that the Conference had an important role in the universalization of human rights as a central point on the agenda of states and as an issue-area in international relations. The second one refers to the Conference as a contribution to the process of flexibility of sovereignty. The article is divided into three areas: first we discuss the background surrounding the Vienna Conference in the 1990s; next we discuss the relationship between human rights and state sovereignty in the international system and, finally, a third section that aims to relate the two movements from the debates of the Conference.

Keywords: Human Rights. International Relations. Vienna conference. Sovereignty.

\section{INTRODUÇÃO}

II Conferência Mundial sobre direitos humanos convocada pela ONU ocorreu
em Viena, 1993, de 14 a 25 de junho. Este evento é de grande magnitude para
so direitos humanos por vários aspectos. Primeiro pela expressão numérica: 171 delegações de Estados, 2000 0NGs (813 como observadoras), totalizando dez mil participantes. Ademais, a Conferência de Viena chama a atenção por ter ocorrido com a maioria dos Estados do mundo independentes, diferente da I Conferência Mundial (Teerã, 1968) ou da Declaração Universal de 1948.

Ao final da Conferência foi aprovada a Declaração e Programa de Ação de Viena - documento mais abrangente adotado pela comunidade internacional sobre direitos humanos - elaborado pelo Comitê de Redação, presidido pelo Brasil.

A afirmação de que a Conferência de Viena se constitui em um marco para os direitos humanos se assenta em duas hipóteses. A hipótese central deste trabalho é que a Conferência, ao ser realizada no pós-Guerra Fria e ao propiciar um espaço de discussão pluralizado (com participação de delegações de diversos Estados, ONGs e outras organizações da sociedade civil), universalizou o debate acerca dos direitos humanos, que, a partir daí, passaram a ser discutidos (mesmo no sentido de contestação) por atores de variadas origens culturais, sociais, políticas 
e econômicas. A outra hipótese, a fim de demonstrar a magnitude da Conferência, parte da idéia de que o evento foi responsável pela intensificação do complexo processo de flexibilização da soberania estatal iniciado no pós-Segunda Guerra.

A fim de problematizar tais hipóteses, será feita uma contextualização e uma discussão inicial da Conferência de Viena. Nessa primeira parte será apresentado o contexto do imediato pós-Guerra Fria, cenário em que o evento foi idealizado. Ainda nessa seção, o processo preparatório e a Conferência em si e seu documento final serão problematizados. Finalizando a seção - e pondo em discussão a hipótese central deste trabalho - serão expostas as discussões sobre a universalidade dos direitos humanos ocorridas na Conferência. A segunda parte servirá à discussão teórica da relação entre direitos humanos e soberania estatal no sistema internacional. Para isso, o debate entre estudiosos de direitos humanos no campo das Relações Internacionais será abordado a partir da classificação proposta por Koerner. Na terceira parte, a análise se voltará de novo à Conferência. A partir da problematização teórica realizada anteriormente, serão discutidos alguns pontos polêmicos do evento relativos à tensão entre direitos humanos e soberania estatal.

\section{CoNTEXTUALIZAÇÃO E DISCUSSÃO INICIAL DA CONFERÊNCIA DE VIENA - CURTO OTIMISMO: PROCESSO PREPARATÓRIO E DOCUMENTO FINAL}

Apesar da Declaração Universal e dos Pactos de 1966 (Pacto dos Direitos Civis e Políticos e Pacto dos Direitos Econômicos, Sociais e Culturais) assinados no âmbito da ONU e da I Conferência Mundial para os Direitos Humanos (Teerã, 1968), os direitos humanos, enquanto tema da agenda internacional, permaneceram durante a Guerra Fria na lógica do conflito ideológico entre EUA e URSS. Em vista disso, grande parte das discussões internacionais acerca do tema e de sua universalização era permeada por esse embate, levando a uma disputa tanto em relação a uma suposta hierarquia das gerações de direitos humanos quanto à referência freqüente às doutrinas de segurança nacional, amparadas na soberania estatal, como argumento para refutar os padrões internacionais de direitos humanos.

Por isso, a partir do fim da Guerra Fria e do triunfo do Ocidente capitalista, formou-se, à primeira vista, segundo Trindade, o ambiente propício para construção de um consenso mundial baseado nos direitos humanos, na 
democracia e no desenvolvimento (TRINDADE, 1993, p. 39). Porém, pôde-se notar naquele mesmo momento, de acordo com Alves, um conflito entre: "A visão ocidental reducionista que localizava nos países subdesenvolvidos a origem de todos os males e, de outro, pela reação das culturas autóctones hipervalorizando o nativismo contra a importação de valores do Ocidente." (ALVES, 2000, p. 4).

Como forma de defender seus governos da crítica ocidental, fosse pela ligação estreita desses governos com a religião (como o Irã), fosse pelo aporte sócio-cêntrico (como a China), alguns países não-ocidentais, mormente asiáticos, adotaram posturas culturalistas. Essas posturas eram anteriores ao fim da Guerra Fria, mas o fim desse conflito deu grande visibilidade a elas, também pelo fato desses posicionamentos cada vez mais se tornarem fortalecidos intelectualmente nos próprios países ocidentais naquele momento (NESS, 1999, p. 4). Esse culturalismo ganhou força como uma resposta ao universalismo propagado pelas potências ocidentais no pós-Guerra Fria. Por isso, o debate acerca dos valores asiáticos ${ }^{2}$ tornou-se fundamental no fortalecimento desse antiuniversalismo particularista 3 . (ALVES, 2000, p. 196).

Esse debate foi gradativamente ganhando espaço, chegando ao plenário da Conferência de Viena, como observou Habermas:

Desde a comunicação do governo de Cingapura sobre os Shared Values (1991), bem como da declaração de Bangcoc (1993), formulada em conjunto com Cingapura, Malásia, Taiwan e China, iniciou-se um debate, como ficou

\footnotetext{
2 A grande crítica dos "valores asiáticos" ao conceito ocidental de direitos humanos se focava no corte individualista desses direitos. Os asiáticos também reivindicavam para si uma concepção de direitos humanos, a qual, a ser menos individualista e mais comunitarista, mereceria igual prioridade em relação à concepção ocidental. Autores, como Habermas, afirmam que essa crítica asiática ao Ocidente em relação ao corte individualista dos direitos humanos é vazia. Habermas vê nesta contestação uma ferramenta retórica dos Estados orientais a ser utilizada para encobrir violações maciças de direitos humanos. (HABERMAS, 2001, p. 157). Contudo, autores orientais afirmam que o Ocidente não consegue ver no comunitarismo e na tradição oriental a presença de uma consciência a respeito da tolerância e da liberdade, que, apesar de serem distintas das concepções ocidentais, também existem (SEN, 1997, p. 27). Além disso, afirmam que a resistência oriental se dá devido ao caráter exageradamente legal e individual da concepção ocidental de direitos humanos, a qual vem sempre acompanhada de um comportamento político hegemônico por parte do Ocidente.

${ }^{3}$ Nesse contexto de declínio daquele otimismo inicial pode-se observar também um fator extremamente relevante e responsável por tal tendência: a exacerbação dos nacionalismos. Nesse sentido, pode-se recordar do ressurgimento, principalmente na Europa Ocidental, dos partidos ultranacionalistas.
} 
patente na Conferência sobre os Direitos Humanos de Viena, no qual dá-se ora 0 embate ora 0 acordo entre as declarações estratégicas dos representantes governistas com as contribuições de intelectuais da oposição e independentes. (HABERMAS, 2001, p. 155).

Foi nesse contexto de mudança que a Conferência foi preparada. Aquele otimismo que estimulou a convocação deu lugar ao receio de que talvez o evento nem mesmo ocorresse, e no caso de ocorrer, se constituir em um retrocesso (RIDING, 1993, p. 1). A entrada dos direitos humanos na agenda internacional provocou ao mesmo tempo certa desconfiança em vários Estados receosos quanto à garantia de suas soberanias, mas também começou a aglutinar cada vez mais atores em torno do tema.

Reuniões preparatórias foram organizadas a fim de preparar o ambiente para a redação de um texto consensual na Conferência. Porém, em vez de fortalecerem a universalidade através do amadurecimento da discussão acerca dos direitos humanos, trouxeram à Conferência discordâncias entre os Estados, o que tornou a redação do documento final muito mais difícil (BOYLE, 1995, p. 81).

A primeira delas foi a Reunião Regional Africana (Tunis, de 2 a 6 de novembro de 1992). Participaram 42 Estados e ONGs, e dela emanou a Declaração de Tunis. Esta Declaração defendeu a universalidade dos direitos humanos independentemente dos sistemas políticos, econômicos e culturais dos Estados - 0 que se coadunava às intenções da Conferência - mas alertou que a promoção e proteção dos direitos humanos deveriam levar em conta as peculiaridades tradicionais de cada sociedade.

A segunda foi a Latino-Americana e Caribenha (San José, Costa Rica, de 18 a 22 de janeiro de 1993). 0 destaque dessa Declaração foi a valorização da tríade direitos humanos-desenvolvimento-democracia (3D). Além da defesa dos princípios de direitos humanos, também foi defendida a criação do Alto Comissariado para os Direitos Humanos da ONU.

A terceira e mais esperada das três reuniões foi a Asiática (Bangkok, de 29 de março a 2 de abril de 1993). Seu documento final consagrou ao mesmo tempo 0 3D, a indivisibilidade e a universalidade dos direitos humanos e a evocação da riqueza, da diversidade cultural e das tradições asiáticas. A ênfase nas particularidades nacionais e regionais e suas diversas bagagens históricas, culturais e religiosas, foi responsável por incitar o debate sobre a universalidade dos direitos humanos na Conferência (ALVES, 2000, p. 13). 
As três reuniões, ao enfatizarem os direitos econômicos, sociais e culturais, o direito ao desenvolvimento e as particularidades culturais de cada região, tornaram mais complexa, mas também mais plural, a construção do consenso na Conferência de Viena.

Vale ressaltar que a Declaração, seu Preâmbulo e o Programa de Ação de Viena são partes articuladas de um único documento, aprovado por consenso, conhecido como Declaração e Programa de Ação de Viena. Este documento, além da defesa de vários princípios de direitos humanos, atribui legitimidade à preocupação internacional para com eles, remetendo-se à hipótese aqui defendida. A abrangência do documento final da Conferência foi responsável por consolidar a importância internacional deste tema no pós-Guerra Fria. Terminada a Declaração, pode-se perceber sua abrangência e complexidade na promoção e proteção dos direitos humanos no mundo todo. Tais características serão transpostas também ao Programa de Ação. A característica principal deste programaé a formulação de recomendações, fundadas nos princípios consagrados pelo preâmbulo e pela Declaração, no sentido de implementar os direitos humanos (ALSTON, 1994, p. 387).

\section{A UNIVERSALIDADE NA CONFERENCIA DE VIENA: POLEMMICA AGLUTINADORA}

0 debate sobre a universalidade dos direitos humanos foi um dos mais importantes da Conferência. Diferente do que é usualmente feito, a polêmica suscitada por tal questão será analisada não como um revés da Conferência. Pretende-se aqui interpretar como essa pauta foi responsável pelo envolvimento, mesmo que muitas vezes contestatório, de uma pluralidade de atores no debate internacional sobre direitos humanos, elevando-o à posição de issue-area universal.

Para Dornelles, "A afirmação da universalidade dos direitos humanos [...] foi um dos pontos mais debatidos para a elaboração da Declaração." (DORNELLES, 2004, p. 189). Segundo Alves,

Com o acirramento das divergências "culturais" que substituíram os enfrentamentos ideológicos da Guerra Fria, a universalidade dos direitos humanos proclamada na Declaração de 1948 voltara a ser seriamente contestada no processo preparatório da Conferência de Viena e continuou a sê-lo no Plenário daquele evento. (ALVES, 2001, p. 13). 
A universalidade foi obtida em meio a discussões polêmicas, permeadas por choques de concepções acerca dos direitos humanos. A consideração dessa polêmica, caracterizada por tais choques, se faz importante por que mostra como a discussão aglutinou e envolveu delegações das mais diversas origens culturais, como China, Portugal, EUA, Cingapura, República Dominicana, Irã e Arábia Saudita.

Essa diversidade de participantes é suficiente para demonstrar a hipótese central deste trabalho. É inegável que os pronunciamentos não foram consensuais e também que tal discussão de princípios não estava prevista na idealização da Conferência e que a sua ocorrência ameaçou um dos pilares dos direitos humanos. Porém, este artigo tenta olhar os pontos positivos de tal acontecimento. 0 amadurecimento dos direitos humanos, enquanto referenciais éticos no plano internacional, depende do estabelecimento de um diálogo contínuo e aberto com a maior variedade possível de participantes e de concepções. Só a manifestação explícita das visões acerca dos direitos humanos, mesmo que visões críticas a eles, pode fomentar sua discussão no plano internacional ${ }^{4}$.

[...] a idéia de que existem direitos humanos universais, que estabelecem um padrão mínimo de dignidade ao qual todos os indivíduos deveriam ter acesso, [...] parece ganhar cada vez mais espaço no plano internacional como atesta, por exemplo, a adoção pela ONU, por unanimidade, de uma nova Convenção Internacional [Conferência de Viena] na área de direitos humanos, em 1993 (REIS, 2006, p. 25).

Devido a isso, pode-se afirmar que a Conferência de Viena constitui-se em um marco para os direitos humanos e uma das grandes responsáveis pela elevação do status do valor dos direitos humanos enquanto referencial ético e de legitimidade no cenário internacional.

\section{A COMPLEXA RELAÇÃO ENTRE DIREITOS HUMANOS E SOBERANIA NO SISTEMA INTERNACIONAL}

Tratando-se de direitos humanos no plano internacional, um grande debate recai sobre a condição soberana do Estado. Percebe-se que a questão da

${ }^{4}$ Para Gómez (2006, p. 4), "A existência do regime internacional dos direitos humanos é a demonstração conclusiva da significação e importância alcançadas pela temática dos direitos humanos no mundo contemporâneo. Vista em perspectiva histórica ampla, esta temática nunca havia logrado tanta legitimação discursiva em termos de atores, esferas de ação e valores, nem tanta proteção jurídica em escala nacional, regional e global, como na época atual." 
universalidade dos direitos humanos é complexa não apenas em sua dimensão cultural e filosófica, mas também na política, posto o caráter estrutural e histórico da soberania vestfaliana para o sistema internacional. Segundo Bull: "[...] levado ao seu extremo lógico, a doutrina dos direitos e deveres humanos sob a lei internacional é subversiva de todo o princípio segundo o qual a humanidade deveria ser organizada como uma sociedade de Estados." (BULL, 2002, p.152).

Gómez identifica, nesse mesmo sentido, as contradições fundamentais do regime internacional dos direitos humanos:

[...] por um lado, o fato de se sustentar no sistema de Estados-nação soberanos, reconhecendo que os Estados são os agentes indispensáveis da implementação e eficácia dos direitos humanos e, ao mesmo tempo, uns dos principais responsáveis por suas violações; e, por outro lado, o fato de revelar-se cada vez mais limitado e impotente para regular, responsabilizar e controlar os impactos negativos das complexas e multifacetadas estruturas e relações de poder global que operam por fora, por cima, por baixo e por meio dos Estados, inclusive dos mais fortes (GÓMEZ, 2006, p. 12).

A fim de fundamentar a posterior discussão empírica, nesta segunda seção será discutido como essa tensão entre direitos humanos e soberania é tratada na literatura de Relações Internacionais.

\section{DEBATE EM DIREITOS HUMANOS INTERNACIONAIS:} SOBERANIA X ORDEM GLOBAL

Percebe-se um processo ambivalente, intensificado no pós-Guerra Fria, entre o ideário dos direitos humanos e o paradigma da soberania estatal, sustentáculo do sistema interestatal vestfaliano.

Os dois pólos opostos do espectro são evidentes. De um lado, há o princípio da soberania com seus muitos corolários [...] de outro, a noção de direitos humanos fundamentais deve ser respeitada. Enquanto o primeiro princípio é a mais óbvia expressão e última garantia da comunidade de estados iguais e independentes horizontalmente organizados, a segunda representa a emergência de valores e interesses [...] que atravessam profundamente preceitos tradicionais da soberania estatal e da não-interferência nas questões internas de outros Estados 5 (BIANCHI, 1999, p. 260).

\footnotetext{
${ }^{5}$ Em referência à todas as citações em inglês, traduzidas livremente pelo autor do artigo, seguirá, em nota de rodapé, a versão original: "The two opposite poles of the spectrum are evident. On the
} 
0 debate contemporâneo em torno dos direitos humanos se coloca em dois eixos: o primeiro se caracteriza pela tensão entre soberania e ordem global, 0 outro se atém à relação entre universalismo e relativismo. Nesta seção, a análise será focada no primeiro eixo, o qual guarda dois pólos teóricos: globalismo e estatalismo $^{6}$ (KOERNER, 2002, p. 90).

Para os estatalistas, os Estados são os atores predominantes nas relações internacionais. Apesar da existência de valores e normas comuns no cenário internacional, há predominância da ordem política estatal sobre a ordem global. Porém, os estatalistas não são céticos aos direitos humanos. Consideram legítimas as pretensões de universalização dos direitos humanos defendidas pelos globalistas. Mas vêem tais pretensões apenas como parâmetros morais de comportamento no sistema internacional e não como condicionantes efetivos dos Estados nacionais. Para os estatalistas:

Os tratados e outros pactos internacionais de caráter mandatório, só criariam obrigações imediatas, ou seja, prestações e contra-prestações de curto prazo e escopo limitado, dada a impossibilidade de seu enforcement efetivo pelas instituições multilaterais. Em suma, não haveria propriamente direito internacional, dada a ausência de um ente político global com capacidade militar suficiente para obrigar o cumprimento das normas internacionais pelos recalcitrantes e desobedientes e, pois, dissuadir violações (KOERNER, 2002, p. 97).

Hurrell alerta para os perigos do enforcement, uma vez que ele pode minar a própria idéia de consenso e auto-imposição que fundamenta a regulamentação internacional, gerando uma desconfiança por parte dos Estados em se comprometer com documentos sobre direitos humanos por receio de intervenção (HURRELL, 1999, p. 284).

one hand, there stands the principle of sovereignty with its many corollaries [... ] on the other, the notion that fundamental human rights should be respected. While the first principle is the most obvious expression and ultimate guarantee of a horizontally-organized community of equal and independent states, the second view represents the emergence of values and interests [...] which deeply [cut] across traditional precepts of state sovereignty and non-interference in the internal affairs of other states" (BIANCHI, 1999, p. 260).

${ }^{6}$ Apesar da clara e reconhecida conexão entre os dois eixos, esta escolha se justifica na fundamentação das hipóteses deste artigo uma vez que não se parte da idéia da universalização dos direitos humanos, mas sim de que a Conferência de Viena elevou os direitos humanos à condição de tema globalmente debatido. 
Krasner considera a soberania estatal como o condicionante determinante na difusão internacional dos direitos humanos. Por isso, concentra sua argumentação na vontade dos Estados e seus governos como condição de sucesso do regime internacional de direitos humanos (KRASNER, 1993, p. 140-141).

Para Hurrell, o Direito Internacional dos Direitos Humanos tem a efetividade ligada a sua incorporação às legislações nacionais. As normas internacionais devem ser minimamente compatíveis com as normas estatais. A partir disso, o Direito Internacional dos Direitos Humanos teria força apenas enquanto fonte do Direito Internacional (HURRELL, 1993, p. 50).

De modo geral, o estatalismo condiciona a efetividade de arranjos de cooperação internacional à aceitação do Estado. Assim, para os estatalistas, as normas internacionais de direitos humanos só adquiririam força vinculante ao adentrarem a constituição nacional, na forma de direitos fundamentais (KOERNER, 2002, p. 98). Daí pode-se afirmar que para o estatalismo a interpretação e, mais do que isso, a implementação dos direitos humanos seriam funções dos sistemas políticos nacionais (e não internacionais ou transnacionais, como quer o globalismo).

Donnelly vê como inviável a efetividade a longo prazo dos tratados de direitos humanos por não existir uma entidade política global com poder suficiente para obrigar o cumprimento e constranger as violações. De acordo com ele, os direitos humanos se caracterizam por serem direitos de caráter moral que tem sua implementação ligada à alçada quase exclusiva dos Estados (DONNELLY, 1999, p. 87).

0 regime global de direitos humanos é majoritariamente um sistema de implementação nacional de normas internacionais de direitos humanos. [...] Políticas de direitos humanos são (na sua maioria) uma parte das políticas externas nacionais, quetodos os Estadosconsideramser regidasprimordialmente pela satisfação do interesse nacional (DONNELLY, 2000, p. 320).

Mas, segundo Donnelly, os direitos humanos, ao contrário do que afirmam os realistas, condicionam e têm seu peso, principalmente no pós-Guerra Fria, enquanto matéria de interesse, apesar de muitas vezes não serem o interesse prioritário, e enquanto linguagem referencial de legitimidade internacional. 0

\footnotetext{
7 "The global human rights regime is largely a system of national implementation of international human rights norms. [...] International human rights policies are (at most) one part of national foreign policies, which all states consider to be driven primarily by the pursuit of the national interest." (DONNELLY, 2000, p. 320).
} 
fato de um interesse ser limitado e de ter um efeito limitado não o desqualifica enquanto interesse. Ainda que marginalmente, esse interesse pode ser levado em conta e, muitas vezes, influenciar o processo decisório ou a formulação da política externa de um país (DONNELLY, 2000, p. 310).

Já o globalismo se caracteriza de modo geral pela predominância da ordem global, que vem se desenvolvendo desde o pós-1945, sobre as demais, isto é, suas normas são superiores aos Estados. Acredita-se na capacidade de transformação do sistema interestatal por meio do reforço a essa ordem global (ARCHIBUGI; HELD; KÖHLER, 1998, p. 2).

Para essa posição [globalismo], as transformações pelas quais a política internacional tem passado desde o final da Segunda Guerra apontam para a formação de uma verdadeira ordem global. [...] [globalistas] têm em comum a proposta de reforçar a ordem global, e, para isso, supõem que é possível transformar 0 sistema interestatal atual, hierárquico, fragmentário, onde parecem prevalecer relações de caráter estratégico entre agentes estatais autointeressados, numa ordem mais estável e integrada, democratizada e promotora da cooperação, a partir de normas e valores consensuais (KOERNER, 2002, p. 92).

Segundo Koerner, para o globalismo "O direito internacional teria adquirido a condição de direito constitucional global, no qual os direitos humanos seriam a carta dos direitos fundamentais, para os direitos estatais, os quais estariam sujeitos à norma de reconhecimento daqueles" (KOERNER, 2002, p. 93).

A argumentação de Held e Archibugi é que com o processo de globalização no pós-Guerra Fria as políticas de um país interferem direta ou indiretamente em cidadãos de outros países, os quais não se pronunciaram acerca dessas decisões. Assim, segundo eles, mesmo que a partir de um ponto de vista estatal esta decisão tenha sido tomada democraticamente, de um ponto de vista cosmopolita ela sofre de um déficit democrático. Daí a necessidade de um sistema internacional permeado universalmente pelos direitos humanos, os quais consideram os indivíduos, e não os Estados, como sujeitos primordiais do sistema.

Archibugi propõe que o paradigma estatal seja articulado e complementado por estruturas mais flexíveis baseadas nos direitos do cidadão global, livre de restrições territoriais:

Se algumas questões a nível mundial devem ser tratadas de acordo com critérios democráticos, deve haver representação política dos cidadãos nos assuntos globais, de forma independente e autônoma de sua representação 
política nos assuntos de âmbito interno. A unidade deve ser o indivíduo, embora os mecanismos de participação e de representação possam variam de acordo com a natureza e 0 âmbito das questões discutidas ${ }^{8}$ (ARCHIBUGI, 1998, p. 212. Grifo nosso).

Held defende que novas constituições políticas sejam criadas, maiores ou menores do que o Estado-nação, dependendo justamente da questão a ser tratada. Propõe um modelo em que as pessoas poderão gozar do senso de pertencimento em diversas comunidades e exercê-lo a partir de variadas formas de participação política.

As pessoas podem desfrutar de pertencimento em diversas comunidades que as afetam significativamente e, consequentemente, ter acesso a uma variedade de formas de participação política. A cidadania seria estendida, em princípio, à participação em todas as comunidades políticas transversais, do local ao global $^{9}$ (HELD, 1995, p. 272).

As argumentações cosmopolitas não descartam o Estado (e a soberania) como esfera legítima. Mas defendem que nos casos em que esta não for suficiente para garantir um funcionamento democrático das relações, outras instâncias, autônomas e independentes, devem atuar legitimadas pelos direitos humanos universais de cidadania global e sem nenhum tipo de constrangimento da estrutura estatal.

Segundo Linklater, "In the new international environment it is both possible and desirable to realize higher levels of universality and diversity that break with the surplus social constraints of the "Westphalian era'." (LINKLATER, 2007, p. 107). Linklater e, de maneira geral, o globalismo vinculam diretamente o tema da cidadania cosmopolita à temática da universalização dos direitos humanos e da consecução de uma ordem global mais justa.

Os globalistas vêem o Direito Internacional dos Direitos Humanos como mandatório. Por isso, seus argumentos teóricos são construídos para fortalecer

\footnotetext{
8 "If some global questions are to be handled according to democratic criteria, there must be political representation for citizens in global affairs, independently and autonomously of their political representation in domestic affairs. The unit should be the individual, although the mechanisms for participation and representation may vary according to the nature and scope of the issues discussed." (ARCHIBUGI, 1998, p. 212. Grifo nosso).

9 "People can enjoy membership in the diverse communities which significantly affect them and, accordingly, access to a variety of forms of political participation. Citizenship would be extended, in principle, to membership in all cross-cutting political communities, from the local to the global." (HELD, 1995, p. 272).
} 
as instituições multilaterais, já que isso reforçaria o referido caráter mandatório. Tendo isso em vista e a intenção de aprofundamento de consensos valorativos para efetivação dos direitos humanos, o globalismo exalta a realização de conferências globais, tal como foi a Conferência de Viena e especialmente a elaboração consensual de Planos de Ação (BOHMAN; LUTZ-BACHMANN, 1997, p. 151).

Essa breve exposição acerca dos argumentos de estatalistas e globalistas é suficiente para demonstrar duas coisas. Primeiro que realmente a tensão entre direitos humanos e soberania estatal é um problema extremamente complexo no campo teórico. Segundo, tendo em vista que tal complexidade teórica se reflete e é reflexo da condição empírica, faz-se necessária a análise de alguns pontos em que esta tensão pôde ser observada durante a Conferência de Viena.

\section{AS MANIFESTAÇÕES DA TENSÃO NA CONFERÊNCIA DE VIENA}

Após a apresentação da Conferência, das discussões sobre a universalidade e da análise teórica, torna-se evidente que a tensão entre direitos humanos e soberania estatal é estrutural quando se pensa em direitos humanos no sistema internacional. Posto isso e para demonstrar a hipótese de que a Conferência de Viena foi uma das grandes responsáveis pela intensificação do complexo processo de flexibilização da soberania estatal iniciado no pós-Segunda Guerra, serão discutidos, nesta seção, alguns pontos específicos do evento concernentes à tensão entre direitos humanos e soberania estatal.

0 primeiro ponto que evidencia essa tensão na Conferência refere-se à criação de um Tribunal Internacional para os Direitos Humanos. Este ponto, dentre os pontos que aqui serão analisados, é o que mais demonstra a resistência do paradigma da soberania estatal frente os direitos humanos. Porém, poderá ser visto que a Conferência, ainda que não de maneira imediata, influiu no processo de flexibilização da soberania estatal.

Tal proposta foi veiculada já na fase preparatória do evento. Apesar do impacto, ela não foi mais do que citada poucas vezes por algumas delegações. Contudo, encontrou ampla defesa das 0NGs e grande veiculação na imprensa. Não houve grande euforia inicial por parte dos Estados na adesão dessa proposta, haja vista que um tribunal desse tipo, de caráter supranacional e permanente em âmbito mundial, representaria um grande avanço no regime internacional dos direitos humanos, o que desafiaria as soberanias dos Estados. 
0 que o Programa de Ação, em seu parágrafo 92, conseguiu foi encorajar o órgão competente da 0NU, no caso a Comissão de Direito Internacional, para prosseguir com seu trabalho sobre um tribunal criminal internacional, já que a Comissão vinha elaborando um projeto de Código de Crimes contra a Paz e a Segurança da Humanidade, não especificamente voltado para os direitos humanos.

Cabe ressaltar que aí está o avanço não imediato promovido pela Conferência, pois após a conclusão do referido código pela Comissão de Direito Internacional, o Tribunal Penal Internacional (TPI), segundo Alves, “[...] instituição extraordinariamente inovadora no sistema das relações internacionais ainda baseado no conceito de soberanias" (ALVES, 2006, p. 24), foi finalmente aprovado com poucos votos negativos na Conferência de Roma de 1998. Com isso, pode-se observar a importância da Conferência de Viena não só no sentido do que ela em si consagrou, mas também enquanto levantadora de questões, as quais ainda seriam amadurecidas futuramente.

Outra discussão ocorrida no processo preparatório da Conferência e com ampla relação com a tensão entre soberania e direitos humanos se deveu à participação das ONGS. As delegações ocidentais eram favoráveis à presença delas. Por outro lado, as delegações não-ocidentais, juntamente com as do Terceiro Mundo, eram extremamente desconfiadas, já que esta forma de organização não fazia parte representativamente de suas sociedades naquele momento. Assim, as viam como instrumento de propagação ideológica das potências ocidentais. Mas ao longo do processo preparatório, a participação das ONGs terminou sendo aprovada.

A segunda sessão do processo preparatório contou com a participação de 77 ONGs (com status consultivo no Ecosoc). Porém, deixou pendente para as sessões seguintes a questão da participação delas nas reuniões regionais preparatórias ${ }^{10}$ (TRINDADE, 1993, p. 6). A terceira sessão recomendou ao Secretário-Geral da

\footnotetext{
${ }^{10}$ Neste aspecto, é importante ressaltar um acontecimento que ilustra a participação das ONGs em Viena. Dias antes da Reunião Asiática intergovernamental, deu-se, também em Bangkok, a Reunião das ONGs de direitos humanos. Esta reunião foi pautada por uma visão diferente quando comparada a sua correspondente interestatal. Isso porque defendeu explicitamente, por exemplo, a proteção à mulher, a democracia participativa e a ratificação universal de tratados de direitos humanos. Nas palavras de Trindade, "A Declaração de ONGs de Bangkok foi bem mais além do que sua equivalente intergovernamental (a Declaração de Bangkok propriamente dita), particularmente no que diz respeito à universalidade dos direitos humanos e a questão da diversidade cultural." (TRINDADE, 1993, p. 21).
} 
ONU que convidasse diferentes categorias de ONGs para as Reuniões Regionais Preparatórias. Ademais, aprovou o Regulamento Provisório da Conferência Mundial de Direitos Humanos, no qual se autorizou a participação das ONGs como observadoras do evento.

A autorização da participação das ONGs em Viena, ainda que como observadoras, proporcionou maior diálogo entre os governos e a sociedade civil não apenas durante todo o evento, mas fomentou uma tendência, juntamente com a Eco-92, que se perpetuaria em todas as grandes conferências globais da década de noventa.

0 Preâmbulo do documento final de Viena foi que consagrou a participação das ONGs e de outros novos atores não-estatais como legítimos no cenário internacional, inclusive estimulando sua ascensão. A Declaração ressaltou a defesa da participação e da importância das ONGs, de seus direitos de atuação e do diálogo com os Estados. 0 Programa de Ação também afirmou, em relação ao direito ao desenvolvimento, ser vital a cooperação entre governos e ONGs a fim de que esse direito avance. Percebe-se no apoio às ONGs a clara intenção da Conferência de Viena em fomentar um movimento internacional articulado em rede no sentido de flexibilizar o paradigma da soberania estatal ${ }^{11}$.

Com o fim da Guerra Fria, o tema dos direitos humanos e a realização da Conferência de Viena, em 1993, liberaram uma oportunidade - ainda que condicionada pela soberania estatal - para a manifestação articulada de atores que tinham até então pouca preponderância no sistema internacional, como as ONGs. Esse fenômeno demonstra a hipótese, aqui defendida, de que a Conferência de Viena foi grande colaboradora para o processo de flexibilização (mas não supressão) da soberania estatal no pós-Guerra Fria.

\footnotetext{
${ }^{11}$ Além da questão do Alto Comissariado, as ONGs influenciaram na questão da discriminação contra a mulher. 0 grupo das mulheres foi um dos mais defendidos durante o evento e, por isso, um dos que recebeu o maior número de referências no documento final. Isso se deveu à grande articulação promovida pelas ONGs de defesa dos direitos das mulheres, as quais, além de estarem em grande número, pressionaram e direcionaram fortemente as discussões. Nas palavras de Chen, "Na Conferência de Viena sobre Direitos Humanos de 1993, o movimento internacional das mulheres, brilhantemente organizado por Charlotte Bunch e suas colegas, forçou os delegados oficiais a reconhecer que os direitos das mulheres eram direitos humanos." Segue a citação original: "At the 1993 Vienna Conference on Human Rights, the international women's movement, brilliantly organized by Charlotte Bunch and her colleagues, forced the official delegates to recognize that women's rights were human rights." (CHEN, 1996, p. 141).
} 
Um dos pontos mais polêmicos, mas também um dos que mais avançaram nesse processo foi a questão da criação do cargo de Alto Comissário para os Direitos Humanos. Esse ponto vinha sendo debatido desde os anos setenta dentro da Subcomissão de Prevenção da Discriminação e Proteção das Minorias e da Comissão dos Direitos Humanos da ONU, mas jamais havia conseguido aprovação. 0 cargo, segundo Reis, "Foi criado [...] com a finalidade de articular as ações das diversas agências da ONU que lidavam com o tema dos direitos humanos." (REIS, 2004, p. 4).

Esta proposta chegou à Conferência de Viena por meio de uma sugestão da Anistia Internacional, o que demonstra a importância da participação das ONGs em Viena. Já no processo preparatório, a proposta foi encampada por muitas delegações, que viam a necessidade de maior coordenação na matéria de direitos humanos. Porsua vez, a proposta era objetada também por várias outras delegações, pois a viam como uma possibilidade de ingerência intrusiva em suas soberanias. Segundo Alves, "Aos adversários da idéia, a figura de um Alto Comissário parecia ser vista como um mecanismo a ser 'teleguiado' pelo Ocidente desenvolvido para o controle exclusivo de direitos civis e políticos no Terceiro Mundo, ameaçador às soberanias nacionais [...]" (ALVES, 2000, p. 23-24).

Afalta de consenso sobre o ponto permaneceu até o fim do evento. 0 Plenário da Conferência se viu obrigado a encaminhar a proposta para a Assembléia Geral colocando-a como prioritária, atendendo tanto aos defensores da proposta, quanto a seus opositores. Assim, a proposta acabou sendo aprovada por consenso em Nova York, na Assembléia Geral de 1993. 0 consenso foi obtido porque se percebeu, ao longo das negociações, que a criação do cargo não constituiria uma ameaça às soberanias estatais.

\section{Considerações finais}

Como pôde ser visto ao longo das seções, a Conferência de Viena, realizada em 1993, conseguiu universalizar o debate sobre direitos humanos. Como se tentou mostrar com a exposição acerca das discussões sobre a universalidade em Viena, talvez seja exagerado afirmar que a Conferência tenha conseguido universalizar os direitos humanos no sistema internacional. Por outro lado, constata-se, por meio da mesma discussão, o êxito da Conferência em universalizar os debates sobre direitos humanos, difundindo-os pelos mais diversos atores e tornando o tema efetivamente uma issue-area universal nas relações internacionais pós-Guerra 
Fria. A universalização do debate passa não apenas pela difusão do tema entre os Estados, mas também pela ascensão e inclusão de novos atores nas discussões internacionais sobre direitos humanos, dentre eles ONGs e indivíduos.

A outra hipótese, articulada à primeira, também se demonstrou ao longo do artigo. A Conferência de Viena, através, principalmente, da universalização do debate, da autorização de participação de atores não-estatais e da legitimação da preocupação internacional, elevou o status da temática direitos humanos, a qual, em essência, não se adéqua totalmente à lógica da soberania estatal. Assim, ao alcançar tais avanços, a Conferência de Viena intensificou o processo de flexibilização da soberania estatal iniciado no pós-Segunda Guerra e catalisado com o fim da Guerra Fria.

Por outro lado, como já dito aqui, a Conferência flexibilizou, mas não suprimiu de forma alguma, a lógica da soberania estatal existente no sistema internacional. As discussões empíricas aqui tratadas demonstram tal constatação. Mais do que isso, a discussão teórica de estatalistas e globalistas, exposta na segunda seção, demonstra a permanência dessa tensão estrutural e a sua complexidade.

Atualmente, até mesmo por obra da própria Conferência de Viena, não apenas a soberania condiciona os direitos humanos, mas também ocorre 0 movimento inverso. Os direitos humanos, ao se fundamentarem por meio da crença de que todos os indivíduos são iguais, e como tais, possuem igual valor intrínseco, desafiam diretamente o paradigma da soberania estatal. Toda ação interna ou internacional, mesmo contrária aos direitos humanos, deve se justificar perante seus defensores atualmente. Isso mostra como a introdução dos direitos humanos enquanto referencial ético para as relações internacionais condicionou relativamente a soberania estatal, o que demonstra a magnitude da Conferência de Viena.

É inegável que a década de noventa e mesmo os dias de hoje, apesar dos reveses do 11/09/2001, assistimos a uma alteração da soberania pelos chamados temas globais. Dentre eles, os direitos humanos se afiguram como grandemente responsáveis por este processo que, catalisado pela Conferência de Viena, fez com que a legitimidade com a preocupação internacional dos direitos humanos avançasse e que o tema fosse alçado à condição de referencial ético para as relações internacionais contemporâneas. 0 Estado necessita atualmente dos direitos humanos enquanto elemento de legitimidade política ou de moralidade internacional. Isso decorre justamente da ascensão, sobre a qual a Conferência de Viena teve grande influência, dos direitos humanos enquanto issue-area universal. 
Com isso, pode-se dizer, portanto, que a Conferência de Viena alcançou um avanço relativo. Relativo porque permanecem ainda limitações sistêmicas aos direitos humanos no sistema internacional, sejam elas de ordem cultural, como se vê nas discussões atuais sobre a universalidade, sejam elas de ordem política, como bem demonstra a resistência da soberania estatal vestfaliana ao aprofundamento dos mecanismos de efetividade. Mas avanço porque, a despeito desses e outros empecilhos, a Conferência de Viena, ao, simultaneamente, alçar o tema à issue-area universal nas relações internacionais e intensificar o processo de flexibilização da soberania estatal, fortaleceu o papel dos direitos humanos enquanto referencial ético e de legitimidade do sistema internacional.

\section{REFERÊNCIAS}

ALSTON, Philip. The UN's human rights record: from San Francisco to Vienna and beyond. Human Rights Quarterly, Riga, v. 16, n. 2, 1994, p. 375-390.

ALVES, José A. Lindigren. Direitos humanos, cidadania e globalização. Lua Nova, São paulo, n. 50, 2000, p. 185-206.

. Relações internacionais e temas sociais: a década das conferências. Brasília: IBRI, 2001.

A declaração dos direitos humanos na pós-modernidade. DHnet: Direitos Humanos na Internet. Natal, 2006. Disponível em: < http://www.dhnet. org.br/direitos/militantes/lindgrenalves/lindgren_100.html>. Acesso em: 21 set. 2006.

ARCHIBUGI, Daniele; HELD, David; KÖHLER, Martin (eds). Re-imagining political community: studies in cosmopolitan democracy. Nova York: Stanford Press, 1998.

ARCHIBUGI, Daniele. Principles of cosmopolitan democracy. In: ARCHIBUGI, Daniele; HELD, David; KÖHLER, Martin (eds). Re-imagining political community. Cambridge: Polity, 1998.

BIANCHI, Andrea. Immunity versus human rights: the Pinochet case. European Journal of International Law, Badia Fiesolana, v. 10, 1999, p. 237-277.

BOHMAN, James; LUTZ-BACHMANN, Matthias (ed.). Perpetual peace: essays on Kant's cosmopolitan ideal. Massachusetts: MIT Press, 1997. 
BOYLE, Kevin. Stock-taking on human rights: The World Conference on Human Rights, Vienna 1993. Political Studies, Elmfield (UK), n. 43, 1995, p. 79-95.

BULL, Hedley. A sociedade anárquica. São Paulo: Imprensa Oficial de São Paulo, 2002.

CHEN, Martha Alter. Engendering World Conferences: the International Women's Movement and the UN. In: GORDENKER, Leon; WEISS, Thomas G. (eds.). NGOs, the UN, and global governance. Boulder: Lynne Rienner, 1996.

DORNELLES, João Ricardo W. A internacionalização dos direitos humanos. Revista da Faculdade de Direito de Campos, Campos dos Goytacazes, ano IV, n. 4, ano V, n. 5, 2003-2004.

DONNELLY, Jack. The social construction of international human rights. In: DUNNE, Timothy; WHEELER, Nicholas. Human rights in global politics. Cambridge: Cambridge Press, 1999.

. An overview. In: FORSYTHE, David P. Human rights and comparative foreign policy. Tokyo: United Nations University Press, 2000.

GÓMEZ, José María. Sobre dilemas, paradoxos e perspectivas dos direitos humanos na política mundial. Radar do Sistema Internacional, ago., 2006. Disponível em: < http://www.rsi.cgee.org.br/documentos/271/1.PDF> . Acesso em 24 mar 2009.

HABERMAS, Jürgen. A constelação pós-nacional: ensaios políticos. São Paulo: Littera Mundi, 2001.

HELD, David. Democracy and the global order: from the modern state to cosmopolitan governance. Nova York: Stanford Press, 1995.

HURRELL, Andrew. International Society and the Study of Regimes - A Reflective Approach. In: RITTBERGER, V. (ed.). Regime theory and international relations. Oxford: Clarendon Press, 1993.

. Power, principles and prudence: protecting human rights in a deeply divided world. In: DUNNE, T.; WHEELER, N. (eds.). Human rights in global politics. Cambridge: Cambridge Press, 1999.

KOERNER, Andrei. Ordem política e sujeito de direito no debate sobre direitos humanos. Lua Nova, São Paulo, n. 57, 2002, p. 87-111.

KRASNER, Stephen D. Sovereignty, Regimes, and Human Rights. In: RITTBERGER, Volker; MAYER, Peter (eds.). Regime theory and international relations. Oxford: Clarendon Press, 1993. 
KRITSCH, Raquel. Direitos humanos universais, estados nacionais e teoria política: algumas questões práticas e conceituais. Filosofia Unisinos, São Leopoldo, n. 6, 2005, p. 213-230.

LINKLATER, Andrew. Critical theory and world politics: citizenship, sovereignty and humanity. New York: Routledge, 2007.

NESS, Peter van (ed.). Debating buman rights: critical essays from the United States and Asia. London: Routledge, 1999.

REIS, Rossana Rocha. Soberania, direitos humanos e migrações internacionais. Revista Brasileira de Ciências Sociais, São Paulo, v. 19, n. 55, 2004, p. 149-163. . 0 lugar da democracia: a sociedade civil global e a questão da cidadania cosmopolita. Perspectivas, São Paulo, v. 30, 2006, p. 15-32.

RIDING, Alan. A bleak assessment as rights meeting nears. The New York Times. 25 abr. 1993. Disponível em: http://www.nytimes.com/1993/04/25/world/a-bleakassessment-as-rights-meeting-nears.html?pagewanted=print. Acesso em 06 jul. 2009.

SEN, Amartya. Human rights and asian values: sixteenth Morgenthau memorial lecture. New York: Carnegie Council on Ethics and International Affairs, 1997.

TRINDADE, Antônio Augusto Cançado. 0 processo preparatório da Conferencia Mundial de Direitos Humanos: Viena, 1993. Revista Brasileira de Política Internacional, Brasília, v. 36, n. 1, 1993, p. 1-45.

Tratado de direito internacional dos direitos humanos. Vol. I. Porto Alegre: S. A. Fabris, 1997. 